BMC

Gastroenterology

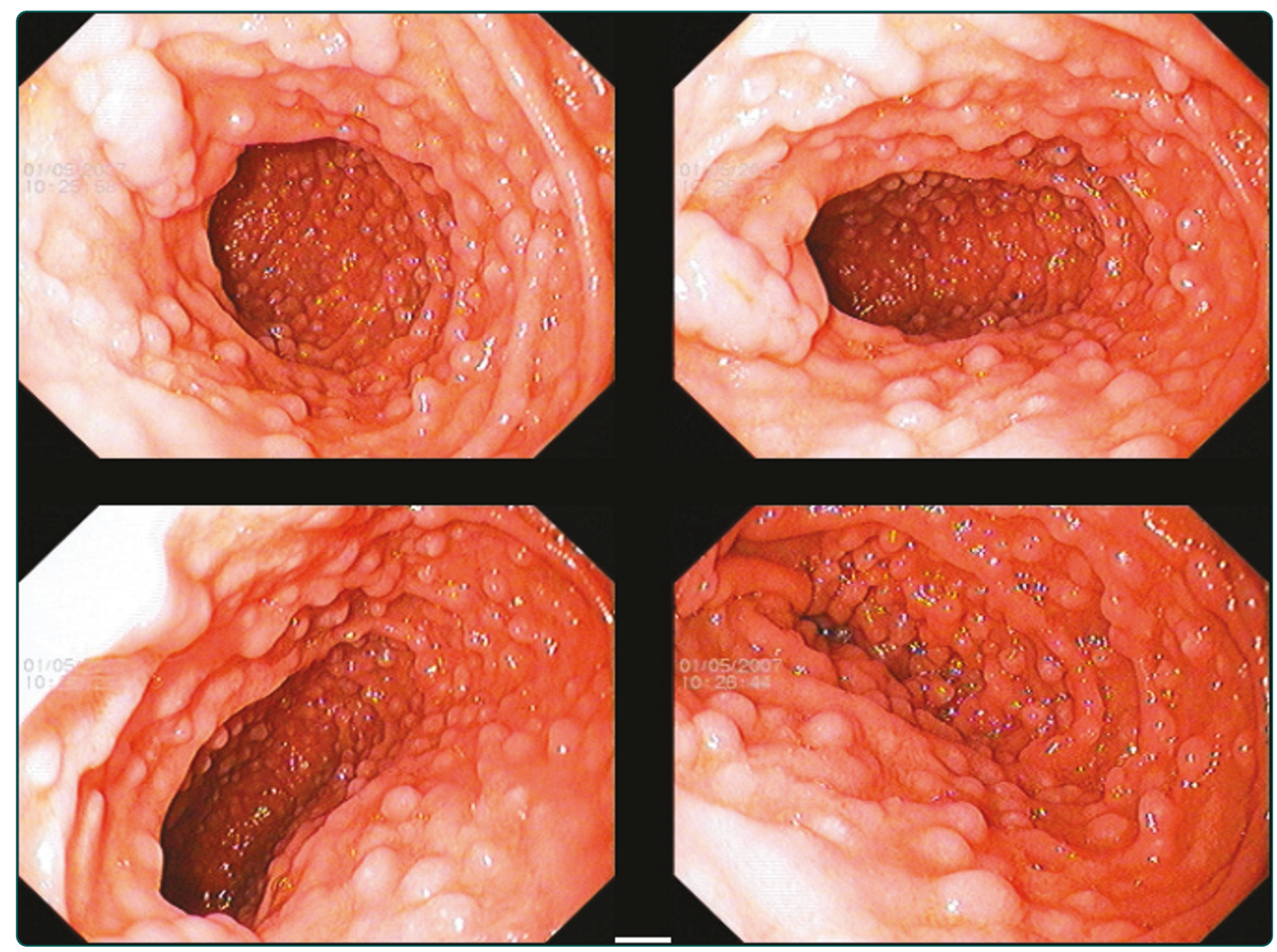

Diffuse duodenal nodular lymphoid hyperplasia: a large cohort of patients etiologically related to Helicobacter pylori infection

Khuroo et al. 


\title{
Diffuse duodenal nodular lymphoid hyperplasia: a large cohort of patients etiologically related to Helicobacter pylori infection
}

\author{
Mehnaaz S Khuroo ${ }^{1}$, Naira S Khuroo ${ }^{2}$ and Mohammad S Khuroo ${ }^{3^{*}}$
}

\begin{abstract}
Background: Nodular lymphoid hyperplasia of gastrointestinal tract is a rare disorder, often associated with immunodeficiency syndromes. There are no published reports of its association with Helicobacter pylori infection.

Methods: From March 2005 till February 2010, we prospectively followed all patients with diffuse duodenal nodular lymphoid hyperplasia (DDNLH). Patients underwent esophagogastroduodenoscopy with targeted biopsies, colonoscopy, and small bowel video capsule endoscopy. Duodenal nodular lesions were graded from 0 to 4 based on their size and density. Patients were screened for celiac sprue (IgA endomysial antibody), immunoglobulin abnormalities (immunoglobulin levels \& serum protein electrophoresis), small intestine bacterial overgrowth (lactulose hydrogen breath test), and Helicobacter pylori infection (rapid urease test, and histological examination of gastric biopsies). Patients infected with Helicobacter pylori received sequential antibiotic therapy and eradication of infection was evaluated by ${ }^{14} \mathrm{C}$ urea breath test. Follow up duodenoscopies with biopsies were performed to ascertain resolution of nodular lesions.
\end{abstract}

Results: Forty patients (Males 23, females 17; mean age \pm 1SD $35.6 \pm 14.6$ years) with DDNLH were studied. Patients presented with epigastric pain, vomiting, and weight loss. Esophagogastroduodenoscopy showed diffuse nodular lesions (size varying from 2 to $5 \mathrm{~mm}$ or more) of varying grades (mean score $\pm 1 \mathrm{SD} 2.70 \pm 0.84$ ) involving postbulbar duodenum. Video capsule endoscopies revealed nodular disease exclusively limited to duodenum. None of the patients had immunoglobulin deficiency or small intestine bacterial overgrowth or positive IgA endomysial antibodies. All patients were infected with Helicobacter pylori infection. Sequential antibiotic therapy eradicated Helicobacter pylori infection in 26 patients. Follow up duodenoscopies in these patients showed significant reduction of duodenal nodular lesions score (2.69 \pm 0.79 to $1.50 \pm 1.10 ; p<0.001)$. Nodular lesions showed complete resolution in 5 patients and significant resolution in remaining 21 patients. Patients with resistant Helicobacter pylori infection showed no significant reduction of nodular lesions score ( $2.71 \pm 0.96$ to $2.64 \pm 1.15 ; p=0.58)$. Nodules partially regressed in score in 2 patients, showed no interval change in 10 patients and progressed in 2 patients.

Conclusions: We report on a large cohort of patients with DDNLH, etiologically related to Helicobacter pylori infection.

\section{Background}

Nodular lymphoid hyperplasia (NLH) of the gastrointestinal tract represents a rare disease that is grossly characterized by the presence of numerous visible mucosal nodules measuring up to, and rarely exceeding, $0.5 \mathrm{~cm}$ in diameter [1]. Histologically, hyperplasic lymphoid follicles with large germinal centres are seen in the lamina propria and

\footnotetext{
* Correspondence: khuroo@yahoo.com

${ }^{3}$ Consultant Gastroenterology, Digestive Diseases Centre, Srinagar, Kashmir, India

Full list of author information is available at the end of the article
}

superficial submucosa [2]. There is enlargement of the mucosal B cell follicles caused by hyperplasia of the follicle centres; surrounded by a normal appearing mantle zone. Disease may involve the stomach, the entire small intestine, and the large intestine [3]. NLH involving the colon can mimic a variety of polyposis syndromes and this may cause difficulties in diagnosis [4]. Disease has been reported to cause pulmonary disease as well [5]. The etiology is unknown. In children, NLH is often associated with viral infection or food allergy; tends to have a benign course and usually regresses spontaneously [6,7]. The disease in adults

\section{Biomed Central}


is rare and poorly described [8]. It has been suggested that $\mathrm{NLH}$ is a risk factor for both intestinal and extra intestinal lymphoma [9-11]. Approximately $20 \%$ of adults with common variable immunodeficiency are found to have NLH [12]. Some patients have low or absent IgA and IgM levels, decreased IgG levels, susceptibility to infection, small intestine bacterial overgrowth, diarrhea with or without steatorrhea [13-16]. Giardia lamblia is often present in such patients [17-19]. There is also an association with familial adenomatous polyposis and Gardner's syndrome [20]. It has also been reported in patients with human immunodeficiency virus infection [21]. The disease may be associated with other pathologies, especially gastrointestinal malignancies [22]. Except an isolated case of gastric nodular lymphoid hyperplasia, there are no published reports of association of NLH with Helicobacter pylori (H. pylori) infection [23]. Here, we report on a large cohort of patients with NLH, etiologically related to $H$. pylori infection.

\section{Methods \\ Study Protocol}

From March 2005 till February 2010, we prospectively followed all patients with diffuse duodenal nodular lymphoid hyperplasia (DDNLH). Patients had detailed history and physical examination. Complete blood counts and serum chemistry were done by standard techniques. Stool analysis was done for ova and parasites. Giardia lamblia infection was evaluated by examinations of concentrated, iodine-stained wet stool preparations; duodenal aspirates and duodenal biopsies. IgA endomysial antibodies were detected by indirect immunofluorescence assay. Serum immunoglobulin (IgG, IgA \& IgM) were estimated by immunoturbidometry. Serum protein electrophoresis was performed by agarose gel electrophoresis and densitometry. Small intestine bacterial overgrowth was evaluated by lactulose hydrogen breath test. Patient underwent esophagogastroduodenoscopy (EGD), targeted gastric and duodenal biopsies, evaluation of $H$. pylori infection; colonoscopies with ileoscopy and video capsule endoscopy. Patients infected with $H$. pylori received 10 days sequential antibiotic therapy. Eradication of $H$. pylori was evaluated by ${ }^{14} \mathrm{C}$ urea breath Test $\left({ }^{14} \mathrm{C}\right.$ UBT $) 4$ to 6 weeks after antibiotic therapy. Patients resistant to sequential therapy received second line antibiotic therapy. Follow up EGD's were performed at/after 6 months of antibiotic therapy to assess the status of the duodenal nodular lesions detected earlier.

\section{Diffuse Duodenal Nodular Lymphoid Hyperplasia (DDNLH)}

Nodular lymphoid hyperplasia was diagnosed when numerous mucosal nodules ( 2 to $5 \mathrm{~mm}$ or more) were visible on endoscopic examination of the gut mucosa and histological examination of the forceps punch biopsies from nodules was reported as NLH [1]. NLH was characterized by presence of well-circumscribed nodes of lymphoid tissue in the lamina propria and/or superficial submucosa. These lymphoid collections showed presence of highly reactive germinal centres, numerous cell types, prominent vascularity and polyclonality as determined immunohistochemically [2]. The extent of nodular lesions was evaluated by various imaging tools including esophagogastroduodenoscopy, colonoscopy with ileoscopy and video capsule endoscopy. Diffuse nodular lesions limited to duodenum were diagnosed as DDNLH.

\section{Esophagogastroduodenoscopy (EGD)}

EGD was performed by an experienced endoscopist (MSK 3) with video-esophago-gastro-duodenoscope (Olympus Evis Smartage Gastro GIF V70 Serial, Olympus Japan). Procedures were video-recorded and representative findings documented on high resolution images using software program. Endoscopic findings were recorded on a proforma. Duodenum was carefully examined for nodules (circumscribed elevated mucosal lesions varying in size from $2 \mathrm{~mm}$ to $5 \mathrm{~mm}$ or more). Nodular lesions in the postbulbar duodenum, second and third part were graded on a scale of 0 to 4 , depending upon the size and density of nodules. Grading was done by 2 investigators (MSK 3/NSK), blinded to results, by reviewing EGD images and recorded video. Prior to actual grading, the scoring system was mutually agreed upon and any discrepancies were mutually discussed and sorted out. Normal duodenum (grade 0) showed prominent smooth closely spaced Valvulae conniventes (Kerckring's folds) without scalloping or nodules. Nodules around 2 to $3 \mathrm{~mm}$ in size and less than 20 in number in the region inspected were reported as grade1. Similar size numerous $(>20)$ nodules which had not deformed the duodenal folds were reported as grade 2 . Grade 3 nodular disease was seen as numerous large ( 2 to $5 \mathrm{~mm}$ ) nodules carpeting the mucosa and causing mucosal fold invasion and deformity. Nodules which were more than $5 \mathrm{~mm}$ in size carpeting the whole duodenal mucosa and obscuring the mucosal folds were reported as grade 4. Multiple (6 or more) forceps biopsies were taken from nodules and the intervening mucosa for histology. Biopsy specimens were examined under light microscopy after staining with hematoxylin and eosin; Periodic Acid Schiff (PAS) and reticulin stains. Immunohistochemistry using CD3 \& CD20 markers was performed to evaluate the cell (T \& B cells) population in the lymphoid nodules. Biopsies were examined for viral inclusions and parasites especially Giardia lamblia [24]. H. pylori infection was evaluated by rapid urease test (RUT) and at histology. For RUT, 2 forceps punch biopsies were taken from gastric incisura 
and embedded in agar gel urea-rich medium (HP test ${ }^{\mathrm{TM}}$, Allied Marketing Corporation, Kolkata, India) and read as per manufacturer's instructions. Multiple gastric biopsies (two from antrum; two from body and additional specimens from any visible endoscopic visible lesions, if needed) were taken and stained with Hematoxylin \& Eosin to type and grade gastritis; Alcian blue to detect intestinal metaplasia and Giemsa stain for $H$. pylori detection and density [25,26].

\section{Colonoscopy}

Colonoscopy with ileoscopy was performed by an experienced endoscopist (MSK) with video-colonoscope (Olympus Evis Smartage Colono CF V70L Serial, Olympus Japan). Forceps biopsies were taken from endoscopic abnormalities as well as terminal ileum.

\section{Video Capsule Endoscopy}

Small bowel video capsule endoscopy was performed on capsule endoscopy system, Rapid 5 UPG with help of Pillcam SB2 capsule (Given Imaging, Ltd. Israel). Video images were examined for presence and extent of nodular lesions in the small bowel.

\section{Lactulose Hydrogen Breath Test}

Small intestinal bacterial overgrowth was evaluated by analyzing breath hydrogen with Gastrolyzer (Bedfont Scientific Ltd. Rochester, Kent, England) after a challenge dose of lactulose $(10 \mathrm{~g})$ and breath samples collected at baseline and subsequent 20 minutes intervals for 3 hours. Positive diagnosis for small intestine bacterial overgrowth was made if the breath hydrogen showed 20 ppm rise above baseline within first 2 hours [27].

\section{H. pylori Eradication}

$H$. pylori eradication was done with sequential antibiotic therapy. Patients received pantoprazole, $40 \mathrm{mg}$, with amoxillin, $1 \mathrm{~g}$, twice daily for 5 days followed by pantoprazole, $40 \mathrm{mg}$, clarithromycin, $500 \mathrm{mg}$, and tinidazole, $500 \mathrm{mg}$, twice daily for next five days [28]. Following sequential therapy, patients received symptomatic treatment including pantoprazole $40 \mathrm{mg}$ per day for next 4 weeks. Patients with resistant $H$. pylori infection to sequential therapy received 10 days second line therapy (pantoprazole $40 \mathrm{mg}$ twice daily along with levofloxacin $750 \mathrm{mg}$ and doxycycline $100 \mathrm{mg}$ once daily). This antibiotic combination was based on $H$. pylori antibiotic sensitivity in this region (Khuroo et al unpublished data).

\section{${ }^{14} \mathrm{C}$ Urea Breath Test $\left({ }^{14} \mathrm{C}\right.$ UBT $)$}

Eradication of $H$. pylori infection after antibiotic therapy was evaluated by ${ }^{14} \mathrm{C}$ UBT using Heliprobe ${ }^{\mathrm{TM}}$ System 2000 (Kibion AB, Uppsala, Sweden). After an overnight fast, patient swallowed a ${ }^{14} \mathrm{C}$ Urea Capsule (HeliCap $\left.{ }^{\mathrm{TM}}\right)$.
After 10 minute wait, patient breathed in to a breath card (BreathCard ${ }^{\mathrm{TM}}$ ) till acid sensitive indicator changed color from orange to yellow suggesting adequate trapping of exhaled breath ${ }^{14}$ Carbon dioxide as lithium carbonate. Breath Card ${ }^{14} \mathrm{C}$ activity was analyzed in a Geiger Muller Counter (Probe ${ }^{\mathrm{TM}}$ ) and $H$. pylori infection analyzed and presented on the display as Heliprobe TM grade 0 (not infected), 1 (Indeterminate) and 2 (Infected).

\section{Ethics}

Written informed consent explaining the indications, adverse affects and alternatives was obtained from all patients before the procedures were carried out. The study protocol was submitted to the ethical committee of Digestive Diseases Centre and was approved. The study protocol conformed to good medical practice as defined in the Helsinki principles.

\section{Statistics}

Comparisons of the categorical variables were analyzed using the Fisher's exact test. Comparisons of the continuous variables were analyzed using the Student's t-test. All values are expressed as mean $\pm \mathrm{SD}$ and frequencies. The statistical analysis was carried out using SPSS for Windows (version 13.0). Two-tailed P values less than 0.05 were considered significant.

\section{Results}

From March 2005 till February 2010, 44 patients with NLH of gastrointestinal tract were diagnosed. Two patients had disease limited to distal ileum as visualized at colonoscopy \& ileoscopy. Another 2 patients had extensive disease involving duodenum, jejunum and ileum. These 2 patients had common variable immunodeficiency syndrome and one of them presented with superadded recurrent Giardia lamblia infection, Remaining 40 patients (Males 23, females 17 ; mean age \pm 1 SD $35.6 \pm 14.6$ years; age range 14 to 62 years) had diffuse nodular disease limited to duodenum and formed the study group (Table 1).

Dominant clinical presentation was epigastric pain, postprandial abdominal distension, vomiting and weight loss. Duration of symptoms varied from 6 months to 5 years (mean \pm 1 SD $2.6 \pm 1.2$ years). Six patients presented with recurrent episodes of diarrhoea, while 4 patients complained of constipation. None of the patients had history suggestive of steatorrhea. Hemoglobin ranged from $6 \mathrm{~g} / \mathrm{dl}$ to $12.5 \mathrm{~g} / \mathrm{dl}$ (mean $\pm 1 \mathrm{SD} 9.5 \pm 2.2 \mathrm{~g} / \mathrm{dl})$. Six patients had severe anemia $(<6.0 \mathrm{~g} / \mathrm{dl}), 22$ patients had moderate anemia ( 6 to $<8 \mathrm{~g} / \mathrm{dl}$ ) and 12 patients had mild anemia ( 8 to $<10 \mathrm{~g} / \mathrm{dl}$ ). Haematological indices revealed iron deficiency anemia in all patients. None of the patients had megaloblastic anemia. Serum albumin ranged from $2.5 \mathrm{~g} / \mathrm{dl}$ to $4.5 \mathrm{~g} / \mathrm{dl}($ mean $\pm 1 \mathrm{SD} 3.2 \pm 1.1 \mathrm{~g} / \mathrm{dl}) .8$ patients had low 
Table 1 The clinical profile of 40 patients with diffuse duodenal nodular hyperplasia

\begin{tabular}{|c|c|c|c|c|}
\hline Group & All patients & $\begin{array}{l}\text { H pylori } \\
\text { eradicated } \\
\text { group }\end{array}$ & $\begin{array}{l}\text { H pylori } \\
\text { persistent } \\
\text { group }\end{array}$ & $\begin{array}{c}\text { P value } \\
\text { (Eradicated vs. } \\
\text { Non-eradicated) }\end{array}$ \\
\hline Number of patients & 40 & 26 & 14 & \\
\hline Age (years $\pm 1 S D$ ) & $35.6 \pm 14.6$ & $33.6 \pm 11.6$ & $37.6 \pm 15.6$ & $0.29 \underline{c}$ \\
\hline Sex (Male: Female) & 23:17 & 15:11 & 8:6 & $0.64 \underline{a}$ \\
\hline \multicolumn{5}{|l|}{$\begin{array}{l}\text { Symptoms } \\
\text { (Number of patients) }\end{array}$} \\
\hline Pain & 40 & 26 & 14 & $1.00 \underline{a}$ \\
\hline Vomiting & 38 & 24 & 14 & $0.41 \underline{a}$ \\
\hline Weight loss & 35 & 23 & 12 & $0.77 \underline{a}$ \\
\hline Diarrhoea & 6 & 4 & 2 & $0.65 \underline{a}$ \\
\hline Constipation & 4 & 1 & 3 & $0.11 \underline{a}$ \\
\hline Hemoglobin (g/dl) & $9.5 \pm 2.2$ & $8.9 \pm 3.2$ & $9.7 \pm 1.2$ & $0.33 \underline{c}$ \\
\hline Serum albumin (g/dl) & $3.2 \pm 1.1$ & $3.4 \pm 1.1$ & $2.9 \pm 1.4$ & $0.39 \underline{c}$ \\
\hline \multicolumn{5}{|l|}{$\begin{array}{l}\text { Immunoglobulins } \\
\text { (Number of patients) }\end{array}$} \\
\hline Normal & 26 & 18 & 8 & $0.14 \underline{a}$ \\
\hline Elevated IgG & 6 & 4 & 2 & $0.65 \underline{a}$ \\
\hline Elevated IgM & 5 & 4 & 1 & $0.41 \underline{a}$ \\
\hline Elevated IgA & 3 & 0 & 3 & $0.03 \underline{a}$ \\
\hline \multicolumn{5}{|l|}{$\begin{array}{l}\text { Gastroscopic findings } \\
\text { (number of patients) }\end{array}$} \\
\hline No abnormality & 8 & 6 & 2 & $0.41 \underline{a}$ \\
\hline Antral gastritis & 20 & 11 & 9 & $0.16 \underline{a}$ \\
\hline Fundic exudative gastritis & 6 & 4 & 2 & $0.65 \underline{a}$ \\
\hline Atrophic gastritis & 4 & 3 & 1 & $0.56 \underline{a}$ \\
\hline Ulcerative Nodular antral disease & 2 & 2 & 0 & $0.41 \underline{a}$ \\
\hline \multicolumn{5}{|l|}{$\begin{array}{l}\text { Grade of duodenal nodular disease } \\
\text { (Number of patients) }\end{array}$} \\
\hline Grade 1 & 4 & 2 & 2 & $0.71 \underline{b}$ \\
\hline Grade 2 & 10 & 7 & 3 & \\
\hline Grade 3 & 20 & 14 & 6 & \\
\hline Grade 4 & 6 & 3 & 3 & \\
\hline Mean \pm 1SD Score & $2.70 \pm 0.84$ & $2.69 \pm 0.79$ & $2.71 \pm 0.96$ & $0.94 \underline{c}$ \\
\hline Follow up months (mean \pm 1SD) & $24 \pm 12.5(6-56)$ & $22 \pm 14.5(6-54)$ & $26 \pm 12.9(8-56)$ & $0.65 \underline{c}$ \\
\hline
\end{tabular}

$\mathrm{a}=$ Fisher's exact test $2 \times 2$ table; $\mathrm{b}=$ Fisher's exact test rxc table; $\mathrm{c}=$ students $\mathrm{t}$ test.

Key: The profile of 26 patients in whom $H$. pylori infection was eradicated and 14 patients in whom $H$. pylori infection was resistant to eradication therapy are compared.

serum albumin. Serum calcium levels were below normal in 10 patients. Immunoglobulin levels were within normal limits in 26 patients. 14 patients had elevated immunoglobulin levels (IgG in 6 patients, IgM in 5 patients, and IgA in 3 patients). Elevated immunoglobulin levels were less than 1.5 times of the upper limit of normal values. None of the patients had low immunoglobulin level. Serum protein electrophoresis showed normal electrophoretic pattern and none of the patients had M band pattern. None of the patients had small intestine bacterial overgrowth as assessed by lactulose hydrogen breath test. IgA endomysial antibodies were negative in all patients. Stool analysis revealed ova of Ascaris lumbricoides in 11 patients. All patients with Ascaris lumbricoides infection received anthelmintic therapy namely mebendazole $100 \mathrm{mg}$ twice daily per oral for 3 days. None of the patients had Giardia lamblia infection as evaluated by examinations of concentrated, iodine-stained wet stool preparations; duodenal aspirates and duodenal biopsies.

EGD showed diffuse nodular duodenal lesions in all patients (Figure 1). Duodenal bulb showed smooth mucosa, devoid of nodules in all patients. Nodular lesions appeared just beyond the apex of the bulb and were prominently seen in the second and third part of the duodenum. Nodular lesions were graded as grade 1 in 4 patients, grade 2 in 10 patients, grade 3 in 20 patients and grade 4 in 6 patients (mean \pm 1 SD grade $2.7 \pm 1.2$ ). All patients showed distensible duodenal lumen and none 


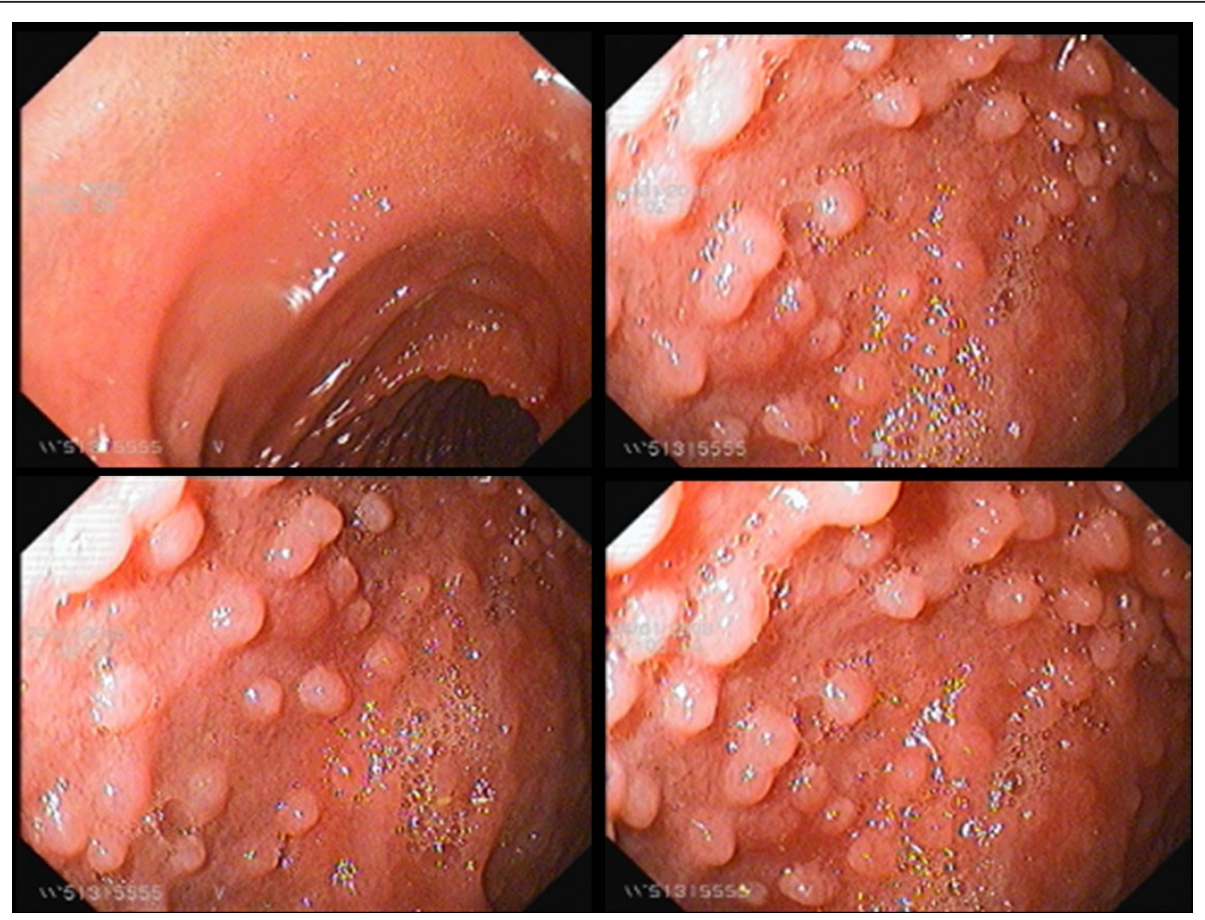

Figure 1 Diffuse Duodenal Nodular Lymphoid Hyperplasia. 35 year male presented with epigastric pain, vomiting and weight loss of $5 \mathrm{~kg}$ over the past 6 months. Duodenal composite images. Top left image: Duodenal bulb revealed smooth mucosa without any nodular lesion. Top right and 2 bottom images: post-bulbar region, second and third part of duodenum showed diffuse numerous mucosal nodules ( $>5 \mathrm{~mm}$ size each) scored as grade 4 disease. There was complete loss of Kerckring's folds. Duodenal biopsies revealed nodular lymphoid hyperplasia. Immunoglobulin revealed mild elevation of lgG level [lgG 2090 mg/dl (normal 700-1600 mg/dl); lgM. 120 mg/dl (normal = 40-230 mg/dl); lgA $145 \mathrm{mg} / \mathrm{dl}$ (normal = 70-400 mg/dl)].

showed luminal narrowing or stricture or stasis or ulcerations. Examination of stomach showed no endoscopic abnormality in 8 patients; linear erythematous antral gastritis in 20 patients; exudative fundic gastritis in 6 patients and atrophic gastritis in 4 patients. Two patients had diffuse ulcerative nodular lesions limited to the antrum. None of the patient had pyloric or duodenal ulcer. RUT was positive in all patients and $H$. pylori were seen in gastric biopsies in all patients. Density of $H$. pylori was moderate in 6 patients and heavy in 34 patients. Histology of gastric biopsies revealed chronic superficial gastritis in 24 patients, and chronic atrophic gastritis with intestinal metaplasia in 14 patients. Two patients with diffuse ulcerative nodular disease of antrum showed histologic features of low grade MALT lymphoma. Duodenal biopsies showed mature nodes of lymphoid follicles in lamina propria (Figure 2). These lymphoid collections showed presence of highly reactive germinal centres. In addition, lamina propria showed mild increase in lymphomononuclear cells. H. pylori were infrequently seen on the duodenal mucosa and in small numbers. Duodenal biopsies lacked features of coeliac sprue namely blunted villi, increased crypt depth, increased crypt villous ratio and epithelial cell lymphocytosis. Immunohistochemistry showed polyclonality of the cellular infiltrate which excludes possibility of duodenal lymphoma. There were no viral inclusions or Giardia lamblia seen in the tissue specimens.

Video capsule endoscopy showed nodular lesions in the postbulbar duodenum, second and third part of duodenum (Figure 3). There was marked reduction in the

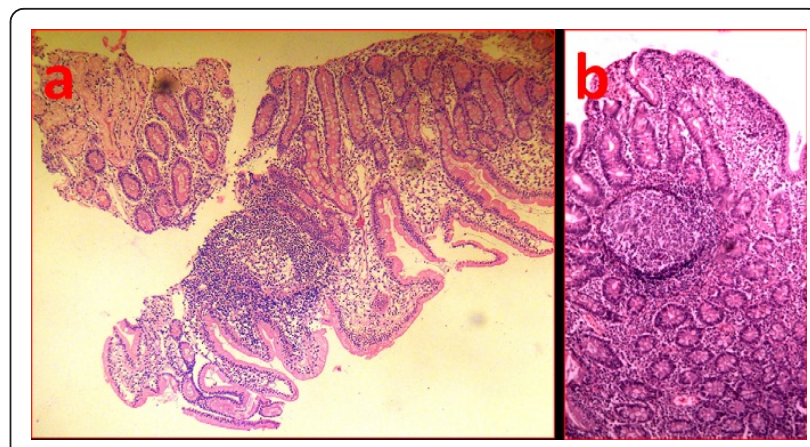

Figure 2 Diffuse Duodenal Nodular Lymphoid Hyperplasia. a) Low power view (H\&E 10X) of duodenal biopsy showing a lymphoid follicle. b) High power view (H\&E 40X) A mature lymphoid follicle with highly reactive germinal centre and surrounding normal appearing mantle zone is seen. There is mild increase in lymphoid infiltrate in the lamina propria. 


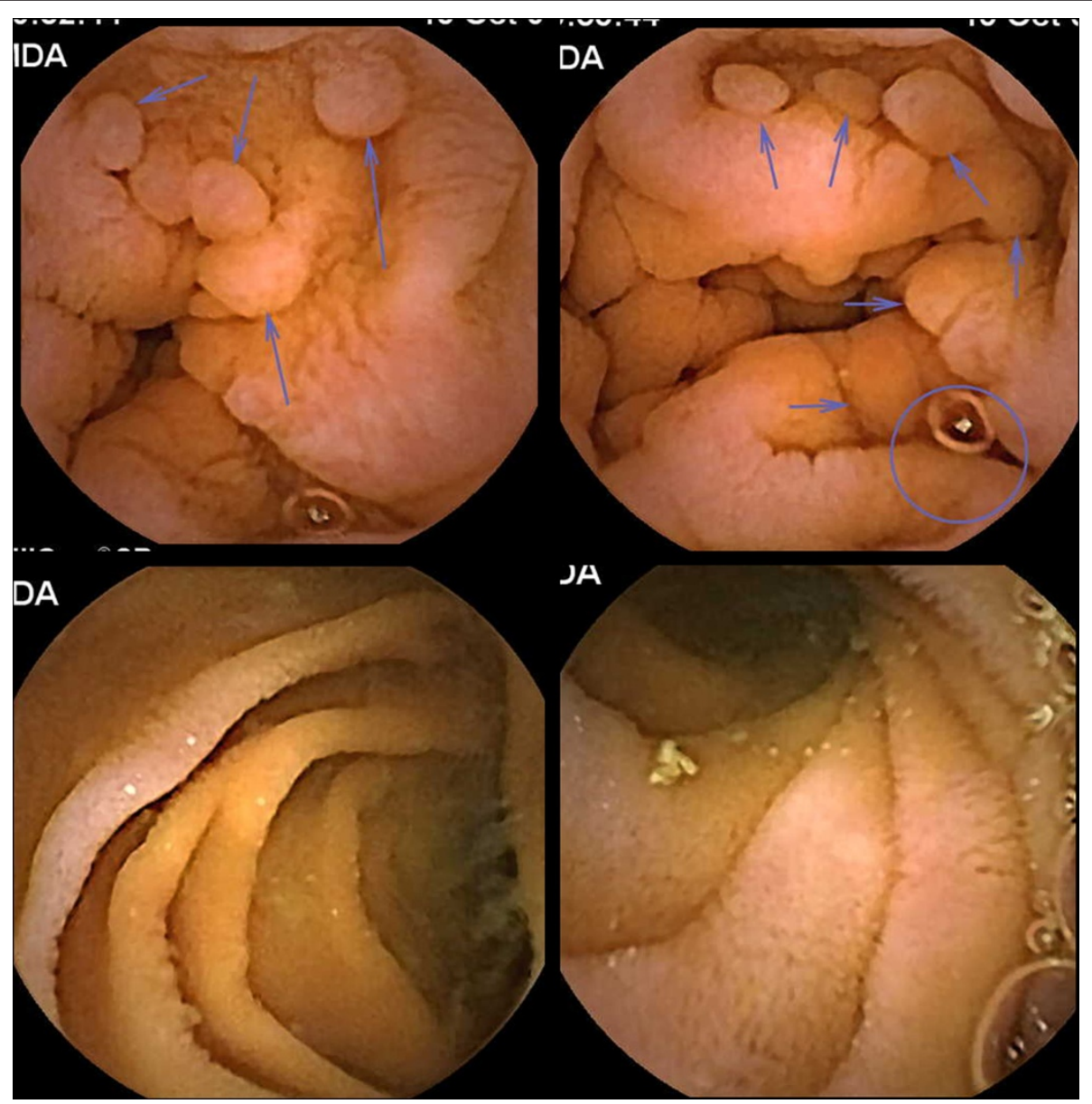

Figure 3 Diffuse Duodenal Nodular Lymphoid Hyperplasia. Video Capsule Endoscopy composite images. Top 2 images: Second and third part duodenum shows carpeting of the mucosa with nodular lesions. Bottom 2 images. Jejunum and ileum showed normal appearing mucosa without any nodular lesions.

number of nodular lesions around the duodeno-jejunal junction. There were no nodular lesions seen in the jejunum and ileum. Colonoscopy and ileoscopy was normal in all cases and biopsies of the terminal ileum did not reveal nodular lymphoid hyperplasia.

All patients received sequential antibiotic therapy. $14 \mathrm{C}$ UBT, done 4 to 6 weeks following antibiotic therapy, revealed eradication of $H$. pylori infection in 22 patients. Another 4 patients had $H$. pylori eradication following second line therapy. Remaining 14 patients had persistent H. pylori infection. Abdominal pain and vomiting showed improvement in 14 of the 26 patients in whom $\mathrm{H}$ pylori had been eradicated $(\mathrm{p}<0.001)$ (Table 2$)$. In contrast only 3 out of 14 patients with persistent $H$. pylori infection had improvement in symptoms $(\mathrm{p}=0.22)$. Follow up duodenoscopies in 26 patients with H. pylori eradicated showed significant reduction of duodenal nodular lesions score $(2.69 \pm 0.79$ to $1.50 \pm 1.10 ; \mathrm{p}<0.001)$. Nodular lesions showed complete endoscopic and histological resolution in 5 patients and significant resolution in remaining 21 patients (Figure 4). Two patients with low grade MALT lymphoma showed endoscopic and histologic resolution of the disease, after $H$. pylori eradication. Patients with resistant $H$. pylori infection showed no significant reduction of nodular lesions score $(2.71 \pm 0.96$ to $2.64 \pm 1.15 ; \mathrm{p}=0.58)$. Nodules regressed in 2 patients, showed no interval change in 10 patients and progressed in 2 patients (Figure 5). Histology of nodules which had progressed over the follow up continued to show polyclonality and there was no suggestion of these nodules evolving in to lymphoma.

\section{Discussion}

NLH of the gastrointestinal tract is a rare disorder, often reported with immune deficiency disorders and/or recurrent giardiasis [11-13,15,17-19]. The disease may be localized to a segment or may affect longer segments of bowel [13]. In contrast to reported disease in literature, the cohort of patients described in this study had significant differences. Firstly the disease was often 
Table 2 The effects of $H$. pylori eradication therapy on $\mathbf{4 0}$ patients with diffuse duodenal nodular hyperplasia

\begin{tabular}{|c|c|c|c|c|c|c|c|c|c|}
\hline \multirow[t]{3}{*}{ Disease severity } & \multicolumn{3}{|c|}{$\begin{array}{l}\text { All patients } \\
(n=40)\end{array}$} & \multicolumn{3}{|c|}{$\begin{array}{l}\text { Eradicated group } \\
\quad(n=26)\end{array}$} & \multicolumn{3}{|c|}{$\begin{array}{l}\text { Not eradicated group } \\
\qquad(\mathrm{n}=14)\end{array}$} \\
\hline & \multicolumn{2}{|c|}{$\begin{array}{l}\text { H. pylori } \\
\text { therapy }\end{array}$} & \multirow[t]{2}{*}{$P$ value } & \multicolumn{2}{|c|}{$\begin{array}{l}\text { H. pylori } \\
\text { therapy }\end{array}$} & \multirow[t]{2}{*}{$P$ value } & \multicolumn{2}{|c|}{$\begin{array}{l}\text { H. pylori } \\
\text { therapy }\end{array}$} & \multirow[t]{2}{*}{$P$ value } \\
\hline & Before & After & & Before & After & & Before & After & \\
\hline Persistent symptoms & 40 & 23 & $<0.001 \mathrm{a}$ & 26 & 12 & $<0.001 a$ & 14 & 11 & $0.22 \mathrm{a}$ \\
\hline \multicolumn{10}{|l|}{ Grade of nodular disease } \\
\hline Grade 0 & 0 & 5 & $0.005 b$ & 0 & 5 & $0.002 b$ & 0 & 0 & $0.91 b$ \\
\hline Grade 1 & 4 & 12 & & 2 & 9 & & 2 & 3 & \\
\hline Grade 2 & 10 & 11 & & 7 & 7 & & 3 & 3 & \\
\hline Grade 3 & 20 & 10 & & 14 & 4 & & 6 & 4 & \\
\hline Grade 4 & 6 & 2 & & 3 & 1 & & 3 & 4 & \\
\hline Mean \pm 1 SD Score & $2.70 \pm 0.84$ & $1.83 \pm 1.06$ & $<0.001 c$ & $2.69 \pm 0.79$ & $1.50 \pm 1.10$ & $<0.001 c$ & $2.71 \pm 0.96$ & $2.64 \pm 1.15$ & $0.58 c$ \\
\hline
\end{tabular}

$\mathrm{a}=$ Fisher's exact test $2 \times 2$ table; $\mathrm{b}=$ Fisher's exact test rxc table; $\mathrm{c}=$ students $\mathrm{t}$ test.

encountered and report of 40 cases from one centre in 5 years period is a testimony to that. Second the disease involvement was limited to postbulbar duodenum, second and third part and duodeno-jejunal junction. Duodenal bulb was spared and there was no involvement of jejunum and ileum. Third none of the patients included in this study had immune deficiency or giardiasis. There are several reports of large cohort of patients similar to described by us from Mexico [16,29]. However, around half of such patients had hypogammaglobinemia.

Diarrhea and weight loss secondary to malabsorption has been the dominant symptom of NLH of small bowel as reported in the literature $[1,15,30,31]$. Malabsorption is a common symptom in patients with immune deficiency with or without superadded recurrent giardiasis [32]. In contrast our patients with DDNLH presented

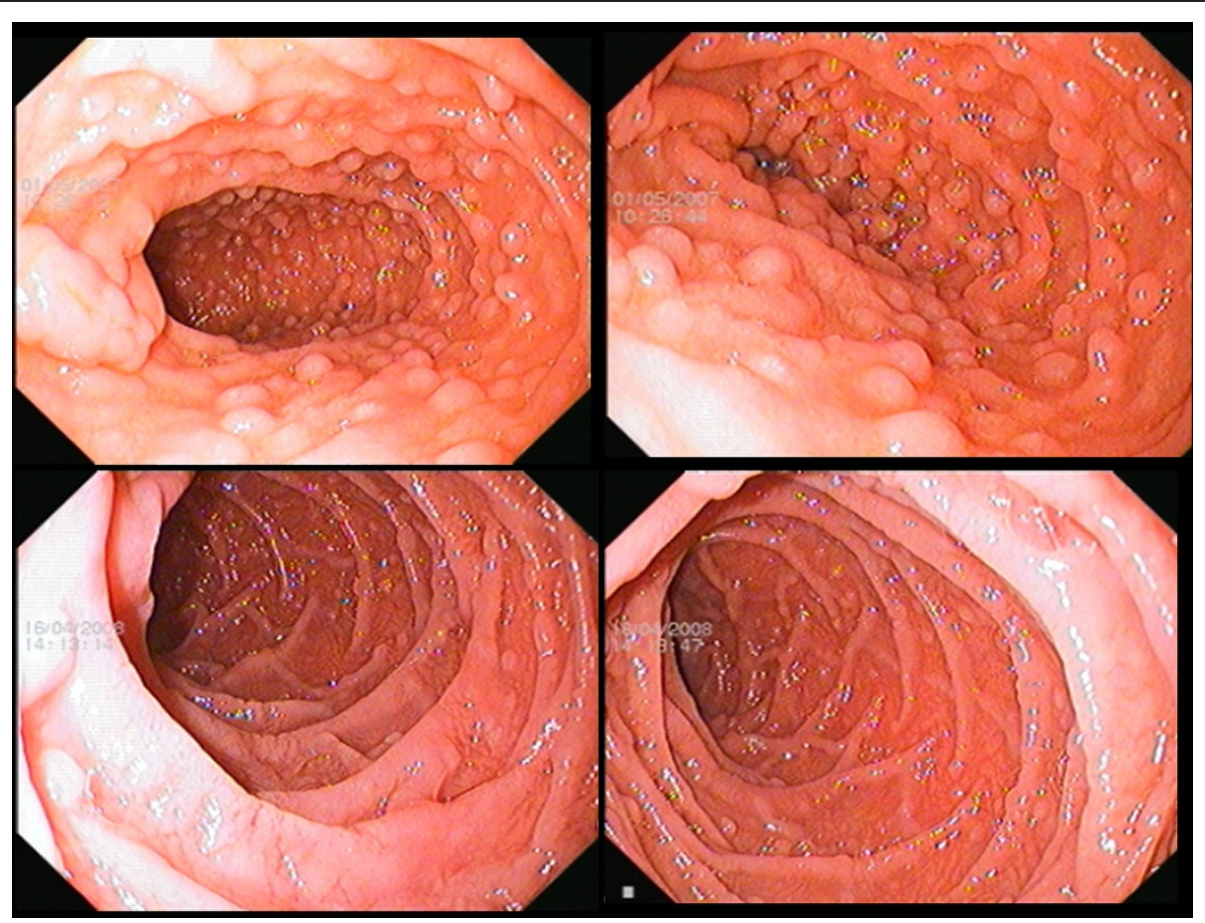

Figure 4 Diffuse Duodenal Nodular Lymphoid Hyperplasia. Duodenal composite images showing effect of H. pylori eradication. 25 year woman presented with recurrent epigastric pain, vomiting and weight loss of $10 \mathrm{~kg}$ over past 2 years. Immunoglobulin levels were within normal limits [lgG $1460 \mathrm{mg} / \mathrm{dl}$ (normal 700-1600 mg/dl); lgM. $190 \mathrm{mg} / \mathrm{dl}$ (normal = 40-230 mg/dl); lgA $230 \mathrm{mg} / \mathrm{dl}$ (normal = 70-400 mg/dl)]. Patient had H. pylori infection with severe fundic exudative gastritis. Top 2 images: Second part of duodenum was carpeted with numerous nodular lesions 3 to $5 \mathrm{~mm}$ in size, scored as grade 3 nodular disease. Patient received $H$. pylori sequential therapy and ${ }^{14} \mathrm{C}$ UBT 6 weeks after therapy showed eradication of infection. Bottom 2 images. Follow up duodenoscopic images at one year showed near complete resolution of the nodular lesions (scored as grade 0). Repeat duodenal biopsies failed to show nodular lymphoid follicles. 


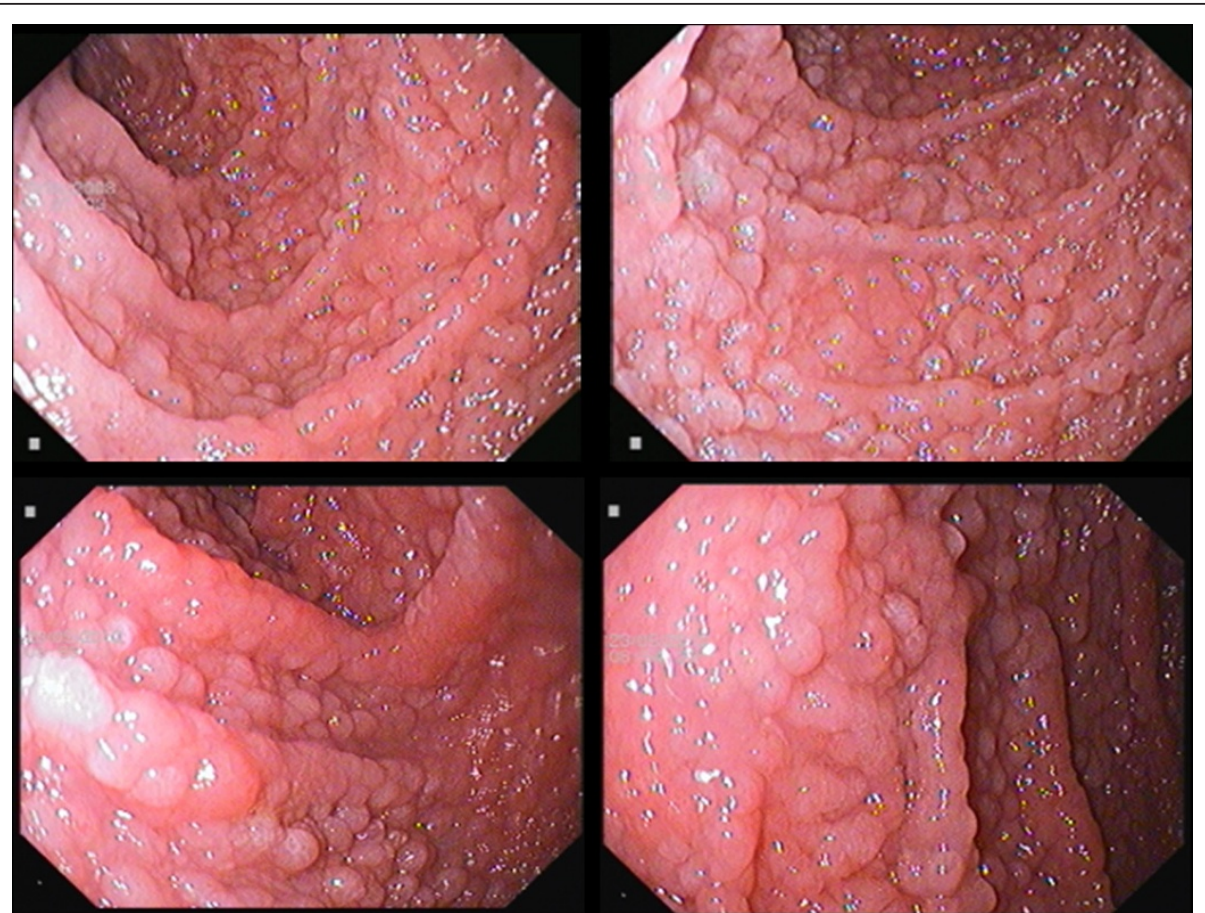

Figure 5 Diffuse Duodenal Nodular Lymphoid Hyperplasia. Duodenal composite images. Progression of disease. 40 year women presented with epigastric pain, vomiting, weight loss and recurrent diarrhoea. IgA levels were elevated [lgG $1400 \mathrm{mg} / \mathrm{dl}$ (normal 700-1600 mg/dl); lgM. $220 \mathrm{mg} / \mathrm{dl}$ (normal = 40-230 mg/d); lgA $540 \mathrm{mg} / \mathrm{dl}$ (normal = 70-400 mg/dl)]. Patient had H. pylori related erythematous antral gastritis. Patient received $H$. pylori eradication sequential therapy followed by Levofloxacin/Doxycycline based second line eradication therapy and ${ }^{14} \mathrm{C}$ UBT showed resistant H. pylori infection. Top 2 images. Duodenal mucosa showed diffuse infiltration with nodules of 3 to $5 \mathrm{~mm}$ size, scored as grade 3 nodular disease. Bottom 2 images at 2 years follow up. There was significant increase in size $(>5 \mathrm{~mm})$ and density of the nodular lesions. Kerckring's folds showed infiltration and focal thickening by nodular disease, scored as grade 4 nodular disease. Biopsies showed nodular lymphoid follicles and infiltrate showed polyclonality of the lymphocytes.

with epigastric pain and vomiting, clinically suggesting gastric stasis and obstruction. Only 6 of our patients presented with diarrhea which may suggest co-existent malabsorption. Weight loss, gastric symptoms, iron lack anemia, and hypoalbuminemia in our patients were mostly caused by selective and dominant involvement of the duodenal mucosa [31].

The pathogenesis of nodular lymphoid hyperplasia has been a matter of debate for long. Histology of these lesions demonstrates hyperplasic lymphoid follicles with mitotically active germinal centres. In immune deficiency states, the lymphoid hyperplasia is likely the result of an accumulation of plasma-cell precursors due to maturational defect in the development of B-lymphocytes [2,29]. These cells attempt to compensate for functionally inadequate intestinal lymphoid function. Bacterial contamination of small intestines is often mentioned as an etiological factor for NLH [16]. This is supported by regression of nodules following oral antibiotic therapy in some cases [32]. Some investigators suggest that coeliac disease may be associated with NLH [1]. However, NLH may occur in a whole spectrum of disorders without any abnormalities in immunoglobulins
[33-35]. It is believed that NLH in absence of immune deficiency disorders may be related to immune stimulation of the gut lymphoid tissue.

H. pylori infection is etiologically associated with a number of gastroduodenal disorders. Acute infection causes neutrophilic gastritis with transient hypochlorhydria and subjects complain of epigastric pain and nausea [36]. Chronic infection causes a wide variety of gastritis including chronic superficial gastritis, nodular gastritis and chronic atrophic corpus gastritis with metaplasia [37,38]. H. pylori infection is strongly associated with peptic ulceration of duodenum and stomach $[39,40]$. Chronic corpus atrophic gastritis with intestinal metaplasia caused by $H$. pylori infection is an initiating event in most cases of intestinal type adenocarcinomas stomach. In fact $H$. pylori infection is associated with both diffuse-type and intestinal-type gastric adenocarcinoma $[40,41]$. Another entity which is etiologically related to $H$. pylori infection is gastric MALT lymphoma. The disease evolves through H. Pylori gastritis with mucosa associated lymphoid tissue (MALT), lymphoepithelial lesions, low grade B cell lymphoma and finally diffuse large B cell lymphoma [42-44]. 
There are no published reports of association of diffuse duodenal nodular lymphoid hyperplasia (DDNLH) with H. pylori infection.

A number of findings strongly pointed to $H$. pylori to be etiologically associated with DDNLH in our patients. All patients were infected with $H$. pylori infection. Patients in whom $H$. pylori were eradicated showed significant clinical response and regression/resolution of duodenal events. In contrast patients in whom H. pylori could not be eradicated showed persistence of clinical symptoms and persistence of duodenal nodular lesions. A number of earlier studies have suggested $H$. pylori as a possible cause of NLH [16,29], but none has followed this lead and none has substantiated this association.

What could be the pathogenesis of DDNLH in our patients? All patients had heavy $H$. pylori infection with advanced changes in the stomach as evidenced by gastroscopic and histological findings. In fact 2 of our patients had low grade MALT lymphoma. However, the duodenal changes seen were not as a result of direct involvement by H. pylori, as the organisms were not consistently present in the duodenal biopsies. A number of nongastrointestinal tract diseases are possibly associated with $H$. pylori infection. Many of these associations are suggested to be related to the effects of $H$. pylori on coagulation and markers of systemic inflammation. We believe the duodenal lesions were as a result of immune stimulation of prolonged and heavy $H$. pylori infection [45]. This was supported by elevated immunoglobulins in a number of patients in our series. Some extragastric disease states are particularly associated with $\mathrm{H}$. pylori CagA-positive infections $[46,47]$. DDNLH seen in our community may be related to high prevalence of such $H$. pylori infections in our community and this need to be explored further. We believe careful examination of post-bulbar and second part of duodenum at EGD and liberal use of duodenal biopsies in patients with heavy $H$. pylori infection in tropical countries is needed to define the impact of this disease.

Two of our patients who failed to eradicate H. pylori infection had disease progression. However, biopsies showed prominent lymphoid follicles with active germinal centres located in the mucosa and there was no suspicion of disease evolving in to lymphoma. NLH has special relationship with lymphoma [7-9]. The disease needs to be differentiated from lymphoma. The presence of highly reactive germinal centres, numerous cell types, prominent vascularity, and polyclonality as determined immunohistochemically are the most important features in the differential diagnosis with lymphoma. Lymphoid hyperplasia may be differentiated from follicular lymphoma presenting as lymphomatous polyposis by $\mathrm{Bcl}-2$ immunostaining of follicular germinal centres. NLH may be a manifestation of extraintestinal lymphoma and disease regresses after extraintestinal lymphoma undergoes remission under chemotherapy [48]. May patients with gastrointestinal lymphoma may present with NLH. Moreover, studies have shown that NLH itself may evolve in to lymphoma on long term follow up. The study period in our patients was not enough to define whether disease can evolve in to lymphoma. Long term follow up of these patients needs to be done to evaluate the malignant potential of this entity.

\section{Conclusions}

In summary, we report on 40 patients with DDNLH. Patients presented with intractable dyspepsia and esophagogastroduodenoscopy showed diffuse nodular lesions of varying grades involving postbulbar duodenum. None of the patients had immunoglobulin deficiency or small intestine bacterial overgrowth or positive IgA endomysial antibodies. All patients were infected with $H$. pylori infection. Sequential antibiotic therapy eradicated $H$. pylori infection in 26 patients. Follow up duodenoscopies in these patients showed significant reduction of duodenal nodular lesions score. Fourteen patients with resistant $H$. pylori infection showed no significant reduction of nodular lesions score. We believe DDNLH in our patients was etiologically related to H. pylori infection.

\section{Acknowledgements}

Funding: This work was conducted at Digestive Diseases Centre, Srinagar, Kashmir, India and was supported by funds from "Dr. Khuroo's Medical Trust".

\section{Author details}

'Lecturer, Department of Pathology, Government Medical college, Srinagar, Kashmir, India. ${ }^{2}$ Consultant Radiology, Digestive Diseases Centre, Srinagar, Kashmir, India. ${ }^{3}$ Consultant Gastroenterology, Digestive Diseases Centre, Srinagar, Kashmir, India.

\section{Authors' contributions}

Contribution by individual authors:

MSK 1 conceived the study; participated in the design of the study; reviewed pathology and performed the statistical work. NSK participated in the design of the study; performed the blind scoring of the endoscopic findings and helped drafting the manuscript. MSK 3 participated in the design of the study; performed the blind scoring of endoscopic findings; and drafted the manuscript. All authors read and approved the final manuscript.

\section{Authors' information}

1. Mehnaaz S Khuroo, MBBS, MD (Pathology), Lecturer, Department of Pathology, Government Medical college, Srinagar, Kashmir, India; Formerly Consultant Pathology, Jawahir Lal Nehru Memorial (JLMN) Hospital Rainawari, Srinagar, Kashmir, India. E-mail: mkhuroo@yahoo.com

2. Naira S Khuroo, MBBS, FIMR (KFSHRC Riyadh), Consultant Radiology,

Digestive Diseases Centre, Srinagar, Kashmir, India. E-mail:

naira_sultan@yahoo.com

3. Mohammad S Khuroo, MBBS, MD, DM, FRCP (Edin), FACP, Master American College of Physicians (MACP, Emeritus), Consultant

Gastroenterology, Digestive Diseases Centre, Srinagar, Kashmir, India. E-mail: khuroo@yahoo.com; visit at: http://www.drkhuroo.com

\section{Competing interests}

The authors declare that they have no competing interests. 
Received: 5 November 2010 Accepted: 11 April 2011

Published: 11 April 2011

\section{References}

1. Ajdukiewicz AB, Youngs GR, Bouchier IAD: Nodular lymphoid hyperplasia with hypogammaglobulinemia. Gut 1972, 13:589-95.

2. Ranchod M, Lewin KJ, Dorfman RF: Lymphoid hyperplasia of the gastrointestinal tract. A study of 26 cases and review of the literature. Am J Surg Pathol 1978, 2:383-400.

3. Molaei M, Kaboli A, Fathi AM, Mashayekhi R, Pejhan S, Zali MR: Nodular lymphoid hyperplasia in common variable immunodeficiency syndrome mimicking familial adenomatous polyposis on endoscopy. Ind J Pathol Microbiol 2009, 52(4):530-3.

4. Schwartz DC, Cole CE, Sun Y, Jacoby RF: Diffuse nodular lymphoid hyperplasia of the colon: polyposis syndrome or normal variant? Gastrointest Endosc 2003, 58:630-2.

5. Abbondanzo SL, Rush W, Bijwaard KE, Koss MN: Nodular lymphoid hyperplasia of the lung: a clinicopathologic study of 14 cases. Am J Surg Pathol 2000, 24:587-97.

6. Colon AR, DiPalma JS, Leftridge CA: Intestinal lymphonodular hyperplasia of childhood: patterns of presentation. J Clin Gastroenterol 1991, 13:163-6.

7. lacono G, Ravelli A, DiPrima L, Scalici C, Bolognini S, Chiappa S, Pirrone G, Licastri G, Carroccio A: Colonic lymphoid nodular hyperplasia in children: relationship to food hypersensitivity. Clin Gastroenterol Hepatol 2007, 5:361-6.

8. Ersoy E, Gundogdu H, Ugras NS, Aktimur R: A case of diffuse nodular lymphoid hyperplasia. Turk J Gastroenterol 2008, 19(4):268-70.

9. Ryan JC: Premalignant conditions of the small intestine. Semin Gastrointest Dis 1996, 7:88-93,

10. Matuchansky C, Touchard G, Lemaire M, Babin P, Demeocq F, Fonck Y, Meyer M, Preud'Homme JL: Malignant lymphoma of the small bowel associated with diffuse nodular lymphoid hyperplasia. N Eng J Med 1985, 313:1666-71

11. Castellano G, Moreno D, Galvao O, Ballestin C, Colina F, Mollejo M, Morillas JD, Solis Herruzo JA: Malignant lymphoma of jejunum with common variable hypogammaglobulinemia and diffuse nodular hyperplasia of the small intestine. A case study and literature review. J Clin Gastroenterol 1992, 15:128-35.

12. Washington K, Stenzel TT, Buckley RH, Gottfried MR: Gastrointestinal pathology in patients with common variable immunodeficiency and X-linked agammaglobulinemia. Am J Surg Pathol 1996, 20:1240-52.

13. Crabbe PA, Heremans JF: Selective IgA deficiency with steatorrhea. Am J Med 1967, 42:319-26.

14. Al Samman M, Zuckerman MJ, Mohandas A, Ting S, Hoffpauir JT: Intestinal nodular lymphoid hyperplasia in a patient with chronic diarrhea and recurrent sinopulmonary infections. Am J Gastroenterol 2000, 95:2147-9.

15. Anderson FL, Pellegrino ED, Schaefer JW: Dysgammaglobulinemia associated with malabsorption and tetany. Am J dig Dis 1970, 15:279-86.

16. Castaneda-Romero B, Diaz-Caldelas L, Galvan-Guerra E, Sixtos S, Arista J, Uscanga L: Intestinal lymphoid nodular hyperplasia in a patient with acquired dysgammaglobulinemia, chronic diarrhea, and bacterial overgrowth syndrome. Rev Gastroenterol Mex 1993, 58(3):225-8.

17. Milano AM, Lawrence LR, Horowitz L: Nodular lymphoid hyperplasia of the small intestine and colon with Giardiasis. Amer J dis Dis 1971, 16:735-7.

18. de Weerth A, Gocht A, Seewald S, Brand B, van Lunzen J, Seitz U, Thonke F, Fritscher-Ravens A, Soehendra N: Duodenal nodular lymphoid hyperplasia caused by giardiasis infection in a patient who is immunodeficient. Gastrointest Endosc 2002, 55:605-7.

19. Onbasi K, Gunsar F, Sin AZ, Ardeniz O, Kokuludag A, Sebik F: Common variable immunodeficiency (CVID) presenting with malabsorption due to giardiasis. Turk J Gastroenterol 2005, 16(2):111-3.

20. Shull LN Jr, Fitts CT: Lymphoid polyposis associated with familial polyposis and Gardner's syndrome. Ann Surg 1974, 180(3):319-22.

21. Rosen Y: Nodular lymphoid hyperplasia of gut in HIV infection. Am J Gastroenterol 1992, 87:1200-2

22. Koren R, Kyzer S, Ramadan E: Nodular lymphoid hyperplasia of the small bowel associated with two primary colonic adenocarcinomas. Tech Coloproctol 1999, 3:161-3.

23. Misra SP, Misra V, Dwivedi M, Singh PA: Helicobacter pylori induced lymphonodular hyperplasia: a new cause of gastric outlet obstruction. J Gastroenterol Hepatol 1998, 13:1189-92.
24. Monkemuller KE, Bussian AH, Lazenby A, Wilcox CM: Special histologic stains are rarely beneficial for the evaluation of HIV-related gastrointestinal infections. Am J Clin Pathol 2000, 114:387-94.

25. Genta RM, Robaseon GO, Graham DY: Simultaneous visualization of Helicobacter pylori and gastric morphology: A new stain. Hum Pathol 1994, 25:221-6.

26. El-Zimaity HM, Segura AM, Genta RM, Graham DY: Histologic assessment of Helicobacter pylori status after therapy: comparison of Giemsa, DiffQuik, and Genta stains. Mod Pathol 1998, 11:288-91.

27. Bratten JR, Spanier J, Jones MP: Lactulose breath testing does not discriminate patients with irritable bowel syndrome from healthy controls. Am J Gastroenterol 2008, 103(4):958-63.

28. Jafri NS, Hornung CA, Howden CW: Meta-analysis: sequential therapy appears superior to standard therapy for Helicobacter pylori infection in patients naive to treatment. Ann Intern Med 2008, 148:923-31.

29. Tapia AR, Calleros JH, Hernandez ST, Uscanga L: Clinical characteristics of a group of adults with nodular lymphoid hyperplasia: a single center experience. World J Gastroenterol 2006, 12:1945-8.

30. Canto J, Arista J, Hernandez J: Nodular lymphoid hyperplasia of the intestine. Clinico-pathologic characteristics in 11 cases. Rev Invest Clin 1990, 42:198-203.

31. Kasirga E, Gülen H, Simşek A, Ayhan S, Yilmaz O, Ellidokuz E: Coexistence of symptomatic iron-deficiency anemia and duodenal nodular lymphoid hyperplasia due to giardiasis: case report. Pediatr Hematol Oncol 2009, 26(1):57-61.

32. Lai Ping So A, Mayer L: Gastrointestinal manifestations of primary immunodeficiency disorders. Semin Gastrointest Dis 1997, 8:22-32.

33. Tomita S, Kojima M, Imura J, Ueda Y, Koitabashi A, Suzuki Y, Nakamura Y, Mitani K, Terano A, Fujimori T: Diffuse nodular lymphoid hyperplasia of the large bowel without hypogammaglobulinemia or malabsorption syndrome: a case report and literature review. Int I Surg Pathol 2002, 10:297-302.

34. Gryboski JD, Self TW, Clemett A, Herskovic T: Selective immunoglobulin A deficiency and intestinal nodular lymphoid hyperplasia: correction of diarrhea with antibiotics and plasma. Pediatrics 1968, 42:833-6.

35. Rambaud JC, De Saint-Louvent P, Marti R, Galian A, Mason DY, Wassef M, Licht $H$, Valleur P, Bernier JJ: Diffuse follicular lymphoid hyperplasia of the small intestine without primary immunoglobulin deficiency. Am J Med 1982, 73:125-32

36. Graham DY, Opekun AR, Osato MS, El-Zimaity HM, Lee CK, Yamaoka Y, Qureshi WA, Cadoz M, Monath TP: Challenge model for H. pylori infection in human volunteers. Gut 2004, 53:1235-43.

37. Kekki M, Villako K, Tamm A, Siurala M: Dynamics of antral and fundal gastritis in an Estonian rural population sample. Scand J Gastroenterol 1977, 12:321-4.

38. Dwivedi M, Misra SP, Misra V: Nodular gastritis in adults: Clinical features, endoscpic appearance, histological feature and response to therapy. J Gastroenterol Hepatol 2008, 23:943-7.

39. Graham DY, Lew GM, Klein PD, Evans DG, Evans DJ Jr, Saeed ZA, Malaty HM: Effect of treatment of Helicobacter pylori infection on the long term recurrence of gastric or duodenal ulcer: A randomized controlled study. Ann Intern Med 1992, 116:705-8.

40. Marshall BJ: Helicobacter pylori. Am J Gastroenterol 1994, 89(Suppl):S116.

41. Schistosomes Liver flukes and Helicobacter pylori: IARC working group on the evaluation of carcinogenic risks to human. Lyon, France, 7-14 June, 1994. IARC Monogr Eval Carcinog Risks Hum 1994, 61:1.

42. Malfertheiner P, Sipponen P, Naumann M, Moayyedi P, Mégraud F, Xiao SD, Sugano K, Nyrén O, Lejondal , H. pylori-Gastric Cancer Task Force: Helicobacter pylori eradication has the potential to prevent gastric cancer: a state-of-the-art critique. Am J Gastroenterol 2005, 100:2100-15.

43. Parsonnet J, Hansen S, Rodriguez L, Gelb A, Warnke R, Jellum E, Orentreich N, Vogelman J, Friedman G: Helicobacter pylori infection and gastric lymphoma. N Engl J Med 1994, 330(18):1267-71.

44. Bayerdörffer E, Neubauer A, Rudolph B, Thiede C, Lehn N, Eidt S, Stolte M: Regression of primary gastric lymphoma of mucosa-associated lymphoid tissue type after cure of Helicobacter pylori infection. MALT Lymphoma Study Group. Lancet 1995, 345(8965):1591-4.

45. Leontiadis Gl, Sharma VK, Howden CW: Nongastrointestinal tract associations of Helicobacter pylori infection. Arch Intern Med 1999, 159:925-40. 
46. Gasbarrini A, Franceschi F, Armuzzi A, Ojetti V, Candelli M, Torre ES, De Lorenzo A, Anti M, Pretolani S, Gasbarrini G: Extradigestive manifestations of Helicobacter pylori gastric infection. Gut 1999, 45(S1):19-112.

47. Takahashi T, Yujiri T, Shinohara K, Inoue Y, Sato Y, Fujii Y, Okubo M, Zaitsu Y, Ariyoshi K, Nakamura Y, Nawata R, Oka Y, Shirai M, Tanizawa Y: Molecular mimicry by Helicobacter pylori CagA protein may be involved in the pathogenesis of $\mathrm{H}$. pylori-associated chronic idiopathic thrombocytopenic purpura. Br J Haematol 2004, 124:91-6.

48. Jonsson OT, Birgisson S, Reykdal S: Resolution of nodular lymphoid hyperplasia of the gastrointestinal tract following chemotherapy for extraintestinal lymphoma. Dig Dis Sci 2002, 47:2463-5.

\section{Pre-publication history}

The pre-publication history for this paper can be accessed here: http://www.biomedcentral.com/1471-230X/11/36/prepub

doi:10.1186/1471-230X-11-36

Cite this article as: Khuroo et al:: Diffuse duodenal nodular lymphoid hyperplasia: a large cohort of patients etiologically related to Helicobacter pylori infection. BMC Gastroenterology 2011 11:36.

\section{Submit your next manuscript to BioMed Central} and take full advantage of:

- Convenient online submission

- Thorough peer review

- No space constraints or color figure charges

- Immediate publication on acceptance

- Inclusion in PubMed, CAS, Scopus and Google Scholar

- Research which is freely available for redistribution

Submit your manuscript at www.biomedcentral.com/submit
C Biomed Central 